\section{Long Time Thermal Annealing Effects on the Film Morphology and Performance of Polymer Solar Cells with Calcium Electrode}

\author{
Hwajeong Kim, Minjung Shin, and Youngkyoo Kim* \\ Organic Nanoelectronics Laboratory, Department of \\ Chemical Engineering, Kyungpook National University, \\ Daegu 702-701, Korea
}

Received August 6, 2008; Revised November 20, 2008; Accepted November 21, 2008

\section{Introduction}

Recently polymer solar cells have been attractively studied due to their prospective advantage for low-cost conversion of solar energy to electricity. ${ }^{1,2}$ The low-cost advantage is attributed mainly to employing wet processes, such as slit-coating, screen-printing, gravure-printing, which can be performed in atmospheric pressure condition though the formation of electron-collecting electrode needs a simple vacuum chamber at the moment. ${ }^{2}$ Their additional figure of merit is on the simple device structure, namely 'single stack structure', which can extremely reduce the manufacturing cost compared to conventional layered inorganic solar cells. ${ }^{2}$ Realization of the single stack polymer solar cells is basically ascribed to the bulk heterojunction (BHJ) concept that utilizes blends of electron-donating materials and electronaccepting materials. ${ }^{3,4}$

Of various BHJ combinations, blends of regioregular poly (3-hexylthiophene) (P3HT) and 1-(3-methoxycarbonyl)-propyl-1-phenyl-(6,6) $\mathrm{C}_{61}$ (PCBM) have been broadly used for high power conversion efficiency (PCE) polymer solar cells. ${ }^{5-10}$ Achieving the high PCE of P3HT:PCBM solar cells can be primarily attributed to the optimized nanomorphology of the BHJ films by thermal and/or solvent annealing which exploit the self-organization feature of regioregular P3HT., ${ }^{5,8}$ In terms of thermal annealing, most of previous studies have been focused on the short time annealing at relatively high temperatures. ${ }^{5-7}$ However, a long time ( $>2 \mathrm{~h}$ ) annealing has not yet been studied for P3HT:PCBM solar cells with a thin calcium electrode of which thickness is typically in the range of 5-30 nm. ${ }^{6,11}$

In this study we have attempted to anneal P3HT:PCBM blend films and corresponding devices for up to $5 \mathrm{~h}$ (the longest time ever reported). To understand the long time

*Corresponding Author. E-mail: ykimm@knu.ac.kr annealing effect on the device performance, the blend film morphology was measured with the annealing time. In particular, the photoelectrons emitted from the surface region of blend films by exposing an UV light were monitored with the annealing time in order to know the composition change near the surface of blend films upon thermal annealing.

\section{Experimental}

Regioregular P3HT and PCBM were used as received from Merck Chemicals and Nano-C, respectively. $15 \mathrm{mg}$ of P3HT and $15 \mathrm{mg}$ of PCBM (P3HT:PCBM=1:1 by weight) were dissolved in chlorobenzene and then were stirred to achieve a homogeneous solution. On to precleaned indium-tin oxide (ITO) coated glass substrates, $70 \mathrm{~nm}$ thick poly(3,4-ethylenedioxythiophene):poly(styrenesulfonate) (PEDOT: PSS, Baytron P standard grade, HC Stark) layer was deposited and then thermally annealed at $230{ }^{\circ} \mathrm{C}$ for $15 \mathrm{~min}$. On top of the PEDOT:PSS layer, P3HT:PCBM blend films were coated by spin-coating at $1,000 \mathrm{rpm}$ for $1 \mathrm{~min}$, followed by soft-baking at $50{ }^{\circ} \mathrm{C}$ for $15 \mathrm{~min}$. The thickness of resulting blend films was $\sim 100$ $\mathrm{nm}$. One set of these film samples was subject to thermal annealing at $140{ }^{\circ} \mathrm{C}$ for $0 \sim 5 \mathrm{~h}$ for the morphology and photoelectron measurements, whilst another set was transferred into a vacuum chamber system to deposit $\mathrm{Ca}$ (30 $\mathrm{nm}$ thick) and $\mathrm{Al}$ (90 nm thick) electrode (see Figure 1). The fabricated devices were also thermally annealed at the same annealing condition as for the films.

The device performance was measured using a solar cell measurement system equipped with an electrometer (Keithley 2400) and a solar simulator (Newport-Oriel). The incident light intensity was $85 \mathrm{~mW} / \mathrm{cm}^{2}$ at air mass (AM) 1.5 condition. The surface morphology of blend films were measured using an atomic force microscope (AFM, Nanoscope IIIa, Digital Instrument), whilst the photoelectron measurement was performed using photoelectron spectrometer (AC-2, Riken Keiki).

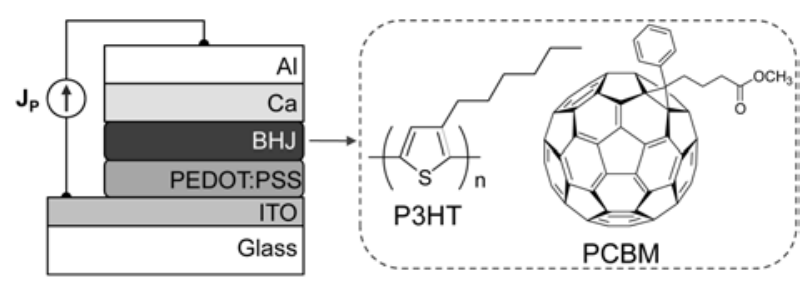

Figure 1. Device structure of polymer solar cells and chemical structure of organic materials for the BHJ layer: $\mathrm{J}_{\mathrm{P}}$ denotes the photocurrent generated. 


\section{Results and Discussion}

The current density - voltage (J-V) characteristics of devices under simulated solar light illumination are shown in Figure 2. The photocurrent part $(-1.1 \sim 0.5 \mathrm{~V})$ of $\mathrm{J}-\mathrm{V}$ curves became more flat for the annealed devices than for the unannealed device, which is in good agreement with previous reports though the thickness of BHJ films is different. ${ }^{5-7,9,10}$ Here the enlarged $\mathrm{J}-\mathrm{V}$ curves show that the trend of short circuit current density $\left(J_{S C}\right)$ is not monotonic with the annealing time (see Figure 2 right). This indicates that the morphology of BHJ films is subject to continuous change with annealing time at this annealing temperature $\left(140^{\circ} \mathrm{C}\right)$ : We note that this trend was confirmed reproducible by repeated experiments.

The improved device performance by thermal annealing can be explained with the trend of dark J-V curves. As shown in Figure 3(left), all the annealed devices exhibited lower base current density in the ohmic current regime ${ }^{12}(<$ $0.15 \mathrm{~V}$ ) compared to the unannealed device [Note that this trend is the same for the reverse bias case in Figure 3 (right)]. However, the current density after the trap-limited
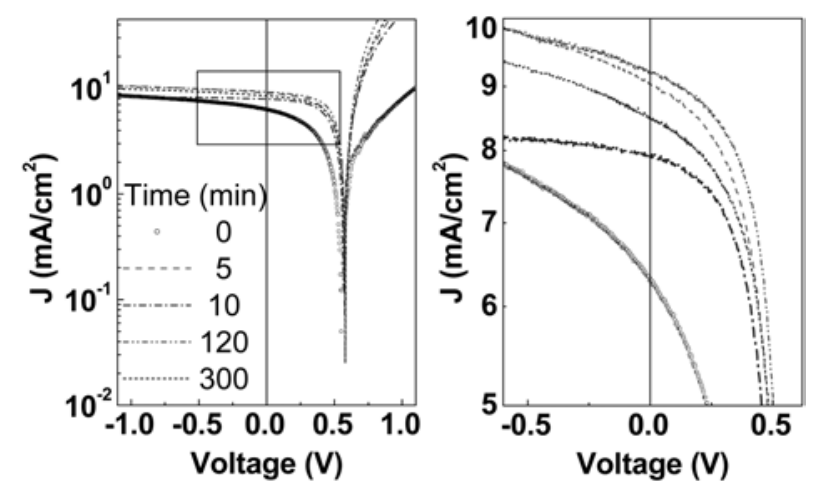

Figure 2. (Left) Light (AM 1.5, $85 \mathrm{~mW} / \mathrm{cm}^{2}$ ) $\mathrm{J}-\mathrm{V}$ characteristics of polymer solar cells with annealing time at $140{ }^{\circ} \mathrm{C}$. (Right) Enlarged J-V characteristics of the left graph marked with a rectangle for better comparison of each curve.
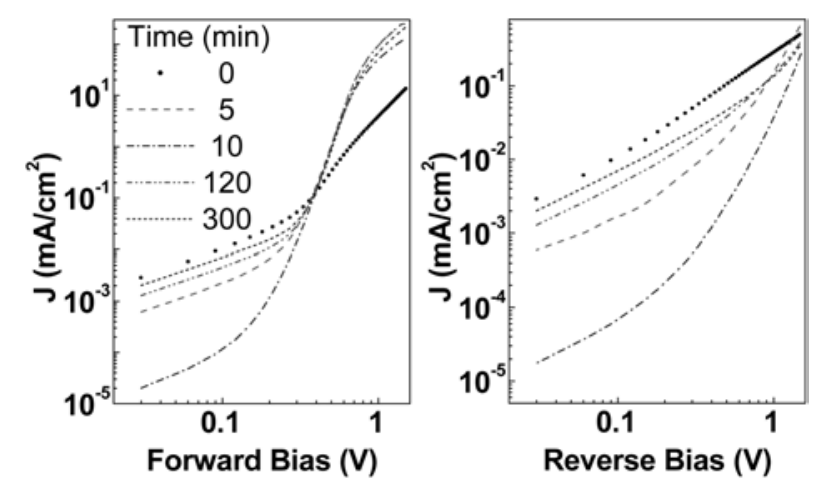

Figure 3. Dark J-V characteristics of polymer solar cells with annealing time at $140{ }^{\circ} \mathrm{C}$ in the direction of forward (left) and reverse (right) bias. current regime $^{12}(>0.4 \mathrm{~V})$ was considerably higher for the annealed devices than the unannealed device. This indicates that the thermal annealing resulted in the greatly improved rectification of devices, indicative of forming better vertical p-n junction morphology in the P3HT:PCBM layer.

Here a particular attention is paid to the device annealed for $5 \mathrm{~h}$ which exhibited still good $\mathrm{J}-\mathrm{V}$ curve shape (PCE $=$ $2.9 \%$ ) though its $J_{S C}$ was reduced from that of the best device (annealed for $2 \mathrm{~h}, \mathrm{PCE}=3.3 \%$ ). This result speaks that the thin $\mathrm{Ca}$ electrode is quite stable under the long time annealing at $140{ }^{\circ} \mathrm{C}$ and the BHJ film morphology might be not much changed though on-going microscopic change is

(a)

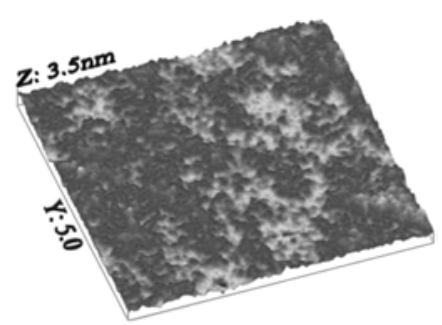

(b)

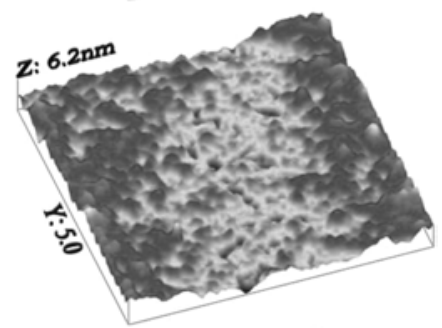

(c)

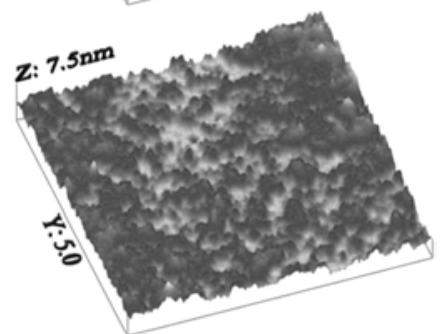

(d)

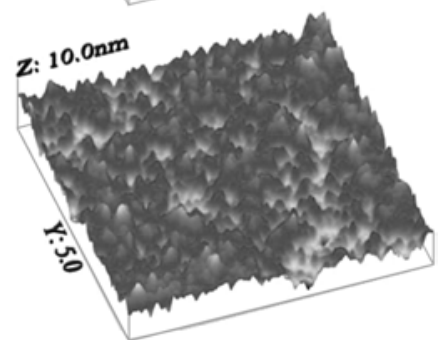

(e)

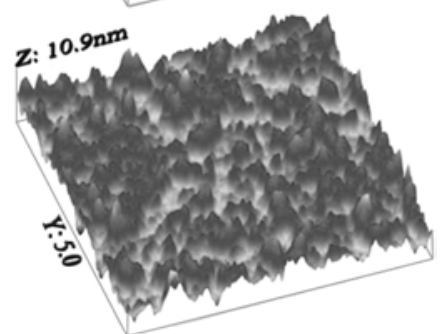

Figure 4. AFM images of P3HT:PCBM blend films annealed for 0 (a), 5 (b), 10 (c), 120 (d), and $300 \mathrm{~min}$ (e) at $140{ }^{\circ} \mathrm{C}$. 
expected with the annealing time as mentioned. This is confirmed with the AFM images in Figure 4. The surface roughness was pronouncedly changed by annealing for up to $2 \mathrm{~h}$, but further annealing for $5 \mathrm{~h}$ led to a small change in the surface roughness within the limited scanning area (Here we note that many microcrystals were observed on the blend film annealed for $5 \mathrm{~h},{ }^{13}$ whilst only surface roughness was changed by 5 min annealing ${ }^{14}$ ).

However, the AFM images provide us with only the surface nanomorphology but no information on the composition change in the surface region. Hence we conducted a photoelectron spectroscopy measurement which enables us to monitor any fluctuation of compositions in the surface region in atmospheric pressure condition. As shown in Figure 5, two distinct zones of photoelectron response were measured for the P3HT:PCBM blend films, which can be attributed to the influence of two constituents, P3HT and PCBM. Here the zone 1 is assigned to the P3HT response, whilst the zone 2 is considered as the mixed response of P3HT and PCBM. We note that only single linear curve is measured for single pristine material (see the pristine P3HT signal in Figure 5) $\cdot{ }^{15}$ In the case of zone 1 the photoelectron response seems to be almost same for all samples. However, the zone 2 response shows large deviations with the annealing time, from which we can get an information on the composition change in the surface region of P3HT:PCBM blend films with the annealing time. As seen from the zone 2 responses, the photoelectron yield of the blend film annealed for $5 \mathrm{~min}$ became steeper than the unannealed film, but more annealing for $10 \mathrm{~min}$ made the yield decreased below the response of the unannealed film. This result delivers that the PCBM content in the surface region ${ }^{16}$ became abundant by the $5 \mathrm{~min}$ annealing and then it was reduced by the 10 min annealing, which is in accordance with the light $\mathrm{J}-\mathrm{V}$ characteristics in Figure 2. Then the yield was increased again by further annealing for $2 \mathrm{~h}$. In particular, the yield was further increased by annealing for $5 \mathrm{~h}$, which can be attributed to the formation of large PCBM microcrystals in the blend films, which was not measured with AFM.

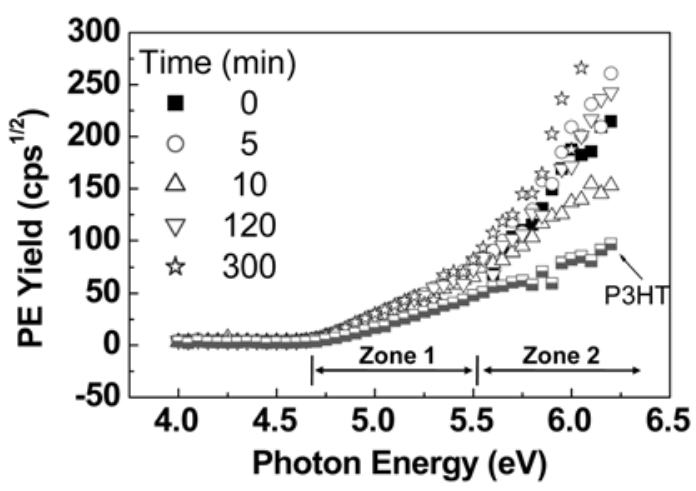

Figure 5. Photoelectron (PE) spectra of P3HT:PCBM blend films with annealing time at $140{ }^{\circ} \mathrm{C}$ and pristine $\mathrm{P} 3 \mathrm{HT}$ film as a reference.

\section{Conclusions}

We found that the performance of P3HT:PCBM solar cells with a thin $\mathrm{Ca}$ electrode was improved by thermal annealing, but its trend was not monotonic with the annealing time. This result could not be explained with the surface morphology measurement, but it was reasonably correlated with the composition changes in the surface region of blend films by the photoelectron spectra measurement. In particular, it is noteworthy that the device performance was not much degraded by the longest time annealing ( $5 \mathrm{~h}$ here), in spite of the formation of PCBM microcrystals, which disclosed the durability of the thin $(30 \mathrm{~nm})$ Ca electrode on top of the P3HT:PCBM blend film upon thermal annealing for such long time at $140^{\circ} \mathrm{C}$.

Acknowledgements. The authors thank Merck Chemicals Ltd for supplying P3HT materials and financial support by the Korea Science and Engineering Foundation (KOSEF) grant (R01-2007-000-10836-0) and the Korea Research Foundation (KRF) grant (KRF-2006-214-E00016).

\section{References}

(1) R. F. Service, Science, 319, 718 (2008).

(2) R. Gaudiana and C. Brabec, Nature Photon., 2, 287 (2008).

(3) N. S. Sariciftci, L. Smilowitz, A. J. Heeger, and F. Wudl, Science, 258, 1474 (1992).

(4) J. J. M. Halls, C. A. Walsh, N. C. Greenham, E. A. Maeseglia, R. H. Friend, S. C. Moratti, and A. B. Holmes, Nature, 376, 498 (1995).

(5) Y. Kim, S. A. Choulis, J. Nelson, D. D. C. Bradley, S. Cook, and J. R. Durrant, Appl. Phys. Lett., 86, 063502 (2005).

(6) G. Li, V. Shrotriya, Y. Yao, and Y. Yang, J. Appl. Phys., 98, 043704 (2005).

(7) M. Reyes-Reyes, K. Kim, and D. L. Carroll, Appl. Phys. Lett., 87, 083506 (2005).

(8) G. Li, V. Shrotriya, J. Huang, Y. Yao, T. Moriarty, K. Emery, and Y. Yang, Nature Mater., 4, 864 (2005).

(9) Y. Kim, S. Cook, S. M. Tuladhar, S. A. Choulis, J. Nelson, J. R. Durrant, D. D. C. Bradley, M. Giles, I. McCulloch, C. S. Ha, and M. Ree, Nature Mater., 5, 197(2006).

(10) M. D. Irwin, D. B. Buchholz, A. W. Hains, R. P. H. Chang, and T. J. Marks, Proc. Nat. Acad. Sci., 105, 2783 (2008).

(11) A. J. Moulé and K. Meerholz, Adv. Mater., 20, 240 (2008).

(12) Y. Kim and C. S. Ha, Advances in Organic Light-Emitting Device, Trans Tech Publications, Switzerland/UK/USA, 2008.

(13) M. Campoy-Quiles, T. Ferenczi, T. Agostinelli, P. G. Etchegoin, Y. Kim, T. D. Anthopoulos, P. N. Stavrinou, D. D. C. Bradley, and J. Nelson, Nature Mater., 7, 158 (2008).

(14) L. H. Nguyen, H. Hoppe, T. Erb, S. Gunes, G. Gobsch, and N. S. Sariciftci, Adv. Funct. Mater., 17, 1071 (2007).

(15) H. Kim, S. Lee, M. Shin, and Y. Kim, manuscript in preparation (2008).

(16) Y. Kim, M. Shin, and H. Kim, Macromol. Res., 16, 185 (2008). 